the operator must next consider what is the best way to remove it, and he has the choice of incising the renal parenchyma or the wall of the pelvis. If the calculus is lying close to the capsule of the kidney it is clear that the easiest and safest method of reaching the stone is by cutting through the tissue covering it, and this should be done by a straight incision with a narrow knife to begin with, and the opening may be enlarged by dilating with dressing forceps, by which the stone may be seized and extracted. When, however, the stone is situated in the pelvis or one of the calyces the question arises, Should the wall of the pelvis or the renal tissue be incised? In respect to this point there is a difference of opinion, some surgeons advocating one method while others with equal enthusiasm support the other mode of operating. But while the two methods are equally satisfactory in respect to the immediate result, in those cases in which the incision has been made through the parenchyma the wound heals more easily and permanent urinary fistulæ have been less common. Stones of large size have been removed by incision into the pelvis, the largest being over two ounces in weight, while by dividing the renal tissue either by the knife or dressing forceps calculi of equal size and weight have been extracted. The bulk of the stone cannot therefore be taken as a guide. When the stone is large it may be broken with a lithotrite or with strong forceps and the fragments and débris removed bit by bit. If at all possible, however, the stone should be removed whole.

When the kidney cannot be delivered in the loin considerable difficulty may be experienced in extracting small smooth stones. They can be felt with the tip of the finger, but when forceps are introduced so as to lay hold of them they recede into the pelvis or une of the calyces, slipping away time after time. Probably the best plan is to get the point of the finger-nail well underneath the stone and press it against a firm portion of the kidney, then gradually work the calculus into the open blades with the forceps, when it may be grasped and removed, or, if this fails, slip a narrow strip of gauze through the wound into the pelvis and gradually manipulate the stone into the fold, and when it becomes entangled there it can be easily laid hold of. Branched stones are often firmly held by strong fibrous bands. These must be carefully divided with scissors, or with the finger-nail, or with forceps, and in all circumstances, if at all possible, the calculus should be extracted unbroken. Rather enlarge the incision freely than run the risk of leaving broken fragments behind, as they are liable to form centres for new concretions.

In cases of old-standing calculous disease the greatest care must taken absolutely to cleanse the whole kidney from deposits, and this is probably best effected by irrigating the carities freely and packing the kidney with gauze so as to establish a free drain which should be kept open as long as any calculous material comes away.

For extraction of a calculus from the ureter the operation to be selected is a matter of considerable moment, and depends upon a careful location of the stone by the methods already described. The procedure depends upon the position occupied by the stone : $(a)$ when the stone is sufficiently low down to be detected by digital examination in the vagina or rectum; $(b)$ when the stone is too high up to be felt by the finger, but occupies the middle third of the ureter; and (c) when the stone is in the upper third of the ureter.

If the stone has passed through the muscular wall of the bladder and pushed the mucous membrane in front of it the appearances presented by the cystoscope are liable to be mistaken for those of tamour. In this situation the stone may be removed by dilatation of the urethra in the female, by suprapubic cystotomy in the male, or by a perineal opening. When the stone has become impacted above the vesical portion of the ureter, but still within the reach of the finger, it should be attacked from below.

In removing a stone from the ureter by an operation through the bladder it may be possible to grasp the impacted body with forceps and, by careful manipulation by means of one finger within the bladder and another in the vagina, drag it away without making any incision in the vesical wall; but if the stone is too large for this it is well to make a small incision and dilate the ureter with sinus forceps before attempting to extract the calculus.

Ceci has removed a ureteral calculus through the rectum, and Fenwick has employed a perineal incision; the removal through the vagina has been employed by Emmett, Cubot, Collerall, Fenwick, Reguey, and others. In such cases above the point of obstruction the ureter is dilated so that it can be easily felt with the finger. The patient should be placed upon her back and the posterior vaginal wall retracted so as to expose the anterior and lateral walls. The ureter and the stone should be fixed by a small sharp hook, one above and another below the stone; an incision is then made through the vaginal wall by cutting on the stone; when the incision is completed a rush of urine takes place and the calculus escapes along with it. A catheter or sound is then passed up the ureter to ascertain that the passage is free above. The opening may be closed with sutures, care being taken to include the outer coats alone, the mucous membrane being carefully excluded from the grip of the stitches; but probably it is safer to keep it open by passing a drainage-tube into the dilated ureter.

When the stone cannot be felt with the finger it must be reached through the abdominal parietes. The ureter may be exposed without opening the peritoneum through an incision similar to the one used in ligaturing the common iliac artery and by retracting the peritoneum, or the line of incision may simply be an extension downwards and inwards of the incision for exploring the kidney. The distance to which the incision is extended inwards and downwards depends upon the necessities of the inclividual case. If the patient is short and stout the space may be extended by making a T-shaped incision or by incising a portion of the quadratus lumborum. When the kidney has been fully exposed a systematic examination must be made of the ureter. The ureter should be carefully searched by grasping the pelvis of the kidney between the forefinger and thumb and passing them downwards, and if a stone be found it may in many instances be reached through the wound in the pelvis by gradually sliding it up in the lumen of the dilated ureter.

Supposing, however, that a stone is not found in the first examination with the kidney in its normal position, the attachments of the organ must be freed and the organ brought out through the wound sufficiently to permit the surgeon to make a thorough inspection. When the hand fails to discover the presence of a stone an incision should be made through the kidney on its outer aspect, and through the wound a digital exploration of the pelvis and calyces should be made, and, if a stone is found, it may be removed. After the stone is extracted a ureteral catheter or sound should be passed down the ureter into the bladder so as to insure that the passage is clear. It is not uncommon to find calculi both in the pelvis and ureter. If a stone is discovered in the lumen of the duct an attempt should be made to press it up towards the kidney, and generally this is easily accomplished, as the ureter is dilated above the point of impaction of the stone, but if it is firmly fixed an incision should be made through the wall of the ureter, and after the calculus has been extracted the incision may be closed by sutures.

Glasgow.

\section{THE ABSORPTION OF PROTEINS.}

\section{By W. D. HALLIBURTON, M.D. LoND., F.R.C.P. LoNd., LL.D., F.R.S.}

PROFESSOR OF PHYSTOLOGY, EING'S COLLEGE, LONDON.

IN one of his recent lectures published in THE LANCET $^{3}$ Dr. F. W. Pavy has alluded to a change that has occurred in my views on the subject of protein absorption since I wrote my first book nearly 20 years ago. I will state as briefly as possible the reasons why my opinions have altered.

If the intestinal epithelium were the exclusive, or even the principal, seat of protein synthesis the coagulable protein in the blood ought to be raised after a protein meal. Recent analyses have shown that this is not the case. If the intestinal lymph were richer in protein during or after digestion than before that act we should then be justified in concluding that this was due to absorption from the alimentary tract; but, again, I do not know of any analyses which lend support to that contention. The sentence Dr. Pavy quotes from my "Chemical Physiology" states that chyle contains more protein than does lymph from the limbs. The statement is correct, but the inference I drew from it in my more youthful days is incorrect. The pericardial fluid is richer in protein 
than the peritoneal lymph, but this does not prove that the pericardium is the seat of protein absorption.

Dr. Pavy asks: "Has recent research done anything to support the view that proteins are split by the digestive juices into their constituent amino-acids, and that these substances pass into the nutrient stream?" To this question I would answer emphatically "Yes," otherwise I should not have adopted this view. In the first place, there has been the discovery of a special ferment (erepsin) which assists the pancreatic juice in cleaving proteins into their simple crystalline products; in the second place, we have the experiments of Loewi, of Abderhalden, and of others which have shown that animals maintain their nitrogenous equilibrium and health when fed exclusively upon these simple materials; thirdly, there are the experiments of Schryver, of Leathes, and of Howell, who have shown that the non-protein nitrogenous constituents of the blood and liver increase after the taking of a protein meal, and they have been successful in the difficult task of detecting in the blood stream some of the individual amino-acids. ${ }^{2}$ Lastly, there has been the discovery by Vernon and others of intracellular enzymes in the various tissues which render the cells capable of dealing with these substances which reach them viâ the blood and lymph.

Dr. Pavy argues that if such simple and small moleculed substances entered the blood-stream they would leave the body rapidly by the urine and he relies upon the analogy with what happens to sugar as a support to this contention. It does not necessarily follow that sugar and amino-acids obey the same laws ; nevertheless, the analogy is sufficiently close, for the amino-acids do rapidly leave the body by the kidneys except that small fraction of them which is utilised by the tissue cells for the purposes of repair. There is, however, between the intestine (the seat of absorption) and the kidneys (the seat of excretion) the large organ known as the liver and this rapidly converts the main bulk of the aminoacids absorbed into urea. When the liver is out of gear this conversion into urea does not occur and then such acids as leucine and tyrosine pass unaltered into the urine. In the normal state traces only of the amino-acids slip as such into the urine. The course of events is therefore precisely, or almost precisely, that which $\mathrm{Dr}$. Pavy considers would occur if the new conception of protein absorption is correct. The large size of the liver renders it adequate to perform this function completely and rapidly. The size of the liver is in striking contrast to the small total weight of the white corpuscles of the blood. Dr. Pary has advanced the view that one kind of colourless corpuscle, the lymphocyte, is mainly concerned in the work of transport from the seat of absorption. The increase in number of Iymphocytes in the blood during digestion certainly takes place, and Dr. Cramer of Edinburgh has to some extent confirmed Dr. Pavy's hypothesis; he regarảs the colourless corpuscles as being concerned "partly at any rate" in the absorption of protein, but the increase noted in their nitrogen during digestion is not due to coagulable protein, but to what he terms "residual nitrogen." He thus shares in the view I have expressed that the products of digestion are not resynthesised into coagulable proteins at the seat of absorption, nor even after ingestion by the lymphocytes. It is impossible to deny that the increase of lymphocytes has some significance, but I have difficulty in believing that this forms such a preponderating factor in absorption as Dr. Pavy imagines. My main difficulty is the small total volume of the lymphocytes even when more are pressed into service after every meal. If they act as porters they must load and unload their burdens with astonishing celerity, and if the unloading of their cargo is accompanied by antolysis or breaking down of the corpuscles themselves, one can only regard the method as more wasteful than Nature's methods usually are.

We may make an approximate estimate of the total weight of the lymphocrtes in the blood as follows. A man of average size weighs 80 kilogrammes; one-twentieth part of this weight consists of blood, so that he will have four kilogrammes of blood. From 35 to 40 per cent. by weight of the blood consists of corpuscles: we will take the larger figure and so the total weight of a man's blood corpuscles will be 1600 grammes. Next the proportion of colourless to coloured corpuscles is on the average 1 in 500 . So that 1-500th part of the total corpuscles will consist of colourless corpuscles, that is, the total weight of the colourless corpuscles in a man's blood is 3.2 grammes. Of these from. 15 to 30 per cent. consist of lymphocytes; giving Dr. Pavy the advantage of the larger figure the total weight of the lymphocytes in a man's blood is just over a gramme, and even if this is doubled during digestion it is difficult to see how two grammes (about 30 grains) of lymphocytes can tackle the enormous burden which every meal must impose upon them.

The only other point I will take up refers to an opinion I expressed concerning a conclusion which Abderhalden has drawn in one of his papers, and I will explain why I hold this conclusion to be reactionary. The question was raised by Abderhalden and Rona in a research which confirmed some work previously performed by Loewi. A growing dog was fed upon the crystalline cleavage products of protein and the dog continued to grow and remained in a healthy condition. They conclude that protein is rebuilt from its cleavage products in the intestinal wall principally because they were unable to discover the amino-acids in the circulating blood during the course of absorption. Ther, however, admit the difficulty of detecting small quantities of such substances in the blood and do not deny the possibility that the tissue-cells generally can build up their protein from simple crystalline material. One may freely grant Abderhalden's general trustworthiness as a chemist; nevertheless, it is always a dangerous practice to draw conclusions from negative results, and he does not refer to the work of others who have succeeded in obtaining positive evidence of the presence of amino-acids in the blood during absorption.

If we accept the dictum that amino-acids are never founds in this situation we are also bound to the view that all the cleavage products of protein cleavage are resynthesised into. protein, and this is a conclusion which is directly contrary to. the great mass of experimental evidence. The whole trend of modern work on metabolism shows that quite a small fraction of the products are ultimately utilised in this way, and that by far the greater part of them undergo exogenous metabolism and are discharged as urea without having been built into protein molecules at all.

Many years ago Kühne argued that the amount of amino. acids in the intestines is so small at any particular moment that complete protein cleavage cannot be considered to occur there to any great extent. He lost sight of the fact that the amino-acids were not formed for the purpose of accumulating there, but for absorption. So with amino-acids in the blood, they are not absorbed in order to be stored in that fluid, but are removed from it by the tissue cells and dealt with there, either for the purpose of assimilation into protoplasm or for discharge as waste material by the kidney. It is only necessary to suppose that this occurs rapidly and this (together with the admitted difficulty of detecting small amounts of amino-acids in the blood) will fully explain Abderhalden and Rona's negative findings.

Another of Abderhalden's investigations ought to have guarded him from drawing what I regard as an erroneous explanation of his results. I refer to that on the behaviour of alanine in the organism of the dog which he undertook in coöperation with Gigon and London. He actually injected a large amount of this amino-acid into the blood stream, and after the lapse of a short time attempted to find it there. Mixed with blood in vitro 3.43 out of four grammes were recovered by the ester method; but mixed with the blood in vivo only a minute fraction was recoverable 20 minutes later. Now if, after the injection of such a massive quantity of amino-acid as eight grammes into the circulating blood, from 98 to 99 hundredths disappear in a few minutes, is it surprising that in the more gradual process of normal absorption it is difficult, or without luck even impossible, to separate out from the circulating fluid a measurable quantity of such substances?

I do not, however, suppose that the last word on protein absorption has yet been written, and we must await further researches to remove the many difficulties which still enshroud this subject.

In his third lecture ${ }^{3}$ Dr. Pavy alludes to an article which I wrote for the Practitioner. ${ }^{4}$ That article did not pretend to be more than an outline sketch of the various views held regarding diabetes from a physiological standpoint, and in a fuller treatise my references to Dr. Pavy's work would hare 
been entirely inadequate. My reference was brief, not becanse I had not studied Dr. Pavy's writings, still less because I desired to be discourteous to him, but simply because I was under the impression (an erroneous one as it turned out) when I wrote the article that Dr. Pavy himself was also going to contribute an article on the subject in the same issue of the Practitioner, and would therefore be able to deal with his own views at greater length. I regard Dr, Pavy's discovery of the carbohydrate radical in the protein molecule, and his work on phloridzin diabetes, to mention only two of the many researches which he has undertaken, as of the highest importance, and later in my article in the Practitioner I agreed that in phloridzin diabetes the blood proteins may act as sugar carriers. I, however, am still doubtful if this is the case in all varieties of diabetes ; and if it is admitted that the sugar may be carried in two ways in disease it is quite possible that when the quantity of sugar is smaller (i.e., in health) it may still be transported in two or more ways.

Facts are one thing and the interpretation of facts is another; and legitimate differences of opinion are inevitable in the present state of our knowledge. We are all anxious to arrive at the truth on this matter as on so many other -disputed problems in physiology. I value Dr. Pary's work I consider his opinion worthy of the fullest consideration, but I nevertheless continue to hold the view prevalent among physiologists, which as I said before is of the nature of a compromise between opposing theories.

Marylebone-road, N.W.

\section{THE TREATMENT OF INGUINAL HERNIA IN CHILDREN.}

BX WILLMOTT H. EVANS, B.S., B.Sc. LoND., F.R.C.S. ENG.,

SURGEON TO THE ROYAL FREE HOSPITAT,

THERE are certain points in connexion with the treatment of inguinal hernia in children on which surgeons are generally agreed, and there are certain other points on which opinions are still widely divided. The points on which agreement for the most part has been reached are, first, that for a certain time after birth a spontaneous cure of an inguinal hernia may result by a continuance of the natural processes of growth which have, for some unknown reason, been delayed, and that the assistance of a truss is generally needed; and secondly, that after this period of time has elapsed a radical cure of the hernia should be performed. There is still, however, a great difference of opinion as to the length of time during which attempts may be made by means of trusses to prerent the descent of the hernia, and so to favour obliteration of the canal of the funicular process; and there is also no agreement as to the exact form of operation required for the radical cure of the hernia when the time has come to operate. The main objects of this paper are two: in the first place I wish to make clear what is the period of time during which, in my opinion, it is wise to try the effect of a truss in the hope of what may be termed a natural cure of the condition, and in the second place to describe that form of radical cure which in my experience is best suited to prevent a recurrence of the hernia.

In a normal child, whether male or female, the obliteration of the processus vaginalis, or funicular process as it is better called, takes place only a short time before birth, certainly within the last month of foetal life and generally within the last two weeks. This obliteration commences at the peritoneal end of the funicular process and it is rarely complete at birth. Delay of a week or two in this obliterative process will result in the persistence of the patency of the canal at birth. There can be little doubt that the canal at birth is very commonly open, so that it may be regarded as hardly abnormal that the closure of the process may commence after birth. Common though it may be that the canal may have delayed its closing until the child is born, yet it is exceptional for the opening to be sufficiently large to admit the entrance of any intestine, so that a congenital hernia is much less common than a patent funicular canal. The natural process of closure may come to completion weeks or even months after birth; but every month that passes by without closure having occurred reduces greatly the chance of closure occurring at all, and when six months have elapsed from birth the chance of a spontaneous closure of the canal, even if aided by the wearing of a truss, is highly improbable. Still, it would be unwise to lay down as an absolute rule that a cure without operation of a congenital inguinal hernia cannot occur eren until somewhere about the end of the first year. For this cure to occur it is essential that on no single occasion any intestine should descend into the sac. For should this happen even once, the obliterative process is checked and the whole of the work has to be done over again. Therefore we cannot expect a non-operative cure unless the greatest care is taken by means of a truss to prevent the descent of the bowel. The question then arises what form of truss is the most suitable for the purpose. I should say at first that however successful the woollen truss may be in restraining the descent of a hernia when it is applied by skilled hands, it is utterly useless to expect any real good from it when it is put on by the mother or nurse. The truss which I consider of the greatest value in congenital inguinal hernia is that which is usually known as the Godlee truss, though I think that a wider pad renders it more valuable. The truss should be made of rubber and should be worn both night and day, and even in the bath.

If, then, a suitable truss has been fitted, the child has worn it for some six months, and during the whole of that time there has been no descent of the hernia, an attempt may be made by disusing the truss to see if a cure has resulted. If the hernia comes down at once it may be taken as certain that a spontaneous cure is exceedingly improbable, and then the question would arise when should an operation be performed.

In the ordinary case of congenital hernia it is usually unnecessary, in my opinion, to advise the performance of an operation during the first year of life, for during the greater part at least of that time a non-operative cure is still possible, and even if it is not likely, the general health of the child may make it advisable to postpone operative treatment. There are, however, certain exceptions. If it is found that no form of truss will suffice to prevent the descent of the hernia, it is obviously useless to attempt or to expect a cure by any method other than operation. Again, there are cases in which the skin has reacted intensely to the pressure and irritation of the truss so that it is in an acutely inflamed condition. In circumstances such as these it is quite impossible to continue truss treatment and means must be taken to effect a cure of the morbid skin condition before further treatment is carried out. After an interval, such as is necessary for this, it is of little use to recommence the use of a truss, even if care has been taken by confinement of the child to bed to prevent the descent of the hernia. In cases such as these an operation is distinctly advisable so soon as the skin has been restored to a thoroughly sound state.

I would lay it down, then, as a rule that during the first year of life operative treatment for congenital inguinal hernia is not advisable except in exceptional circumstances, though when the operation is undertaken the case usually does well. It is often asked if a child while still breast-fed is suitable for a radical cure. Of course, in hospital practice weaning has to precede the operation, but in private practice when there is nothing to hinder the mother being with the child a suckled infant will stand the operation well. In fact, I consider that suckled children stand operations better than children who are being hand-fed.

In the cases which I have been considering the child has been seen during the first few weeks or months of life; but it may happen that an opinion is first asked after the child has reached the age of a year. In these children there is little hope of a cure by truss treatment. Still, it may be tried if any circumstances suggest the postponement of an operation. After two years I think truss treatment is almost useless as a means of cure.

We have now to consider what method of operation is most suitable for these cases of inguinal hernia in children. In this connexion it is important to bear in mind that all these cases are really congenital in origin. I need not enter fully into the controversy whether the presence of a sac or weakness in the abdominal wall is most essential for the production of a hernia, but I may say that, in my opinion, the answer to this question is determined chiefly by the condition of the hernia. In early 